IRA-International Journal of Education \&

Multidisciplinary Studies

ISSN 2455-2526; Vol.10, Issue 03 (March, 2018)

Pg. no. 26-34.

Institute of Research Advances

http://research-advances.org/index.php/IJEMS

\title{
Socio-pragmatic Deficiency in E.Requests
}

\section{Shurooq Abboodi Ali}

Department of English, College of Arts, University of Baghdad, Iraq.

Type of Review: Peer Reviewed.

DOI: http://dx.doi.org/10.21013/jems.v10.n3.p2

\section{How to cite this paper:}

Ali, S.A. (2018). Socio-pragmatic Deficiency in E.Requests. IRA International Journal of Education and Multidisciplinary Studies (ISSN 2455-2526), 10(3), 26-34.doi: http://dx.doi.org/10.21013/jems.v10.n3.p2

(C) Institute of Research Advances.

\section{(cc) EY-NO}

This work is licensed under a Creative Commons Attribution-Non Commercial 4.0 International License subject to proper citation to the publication source of the work.

Disclaimer: The scholarly papers as reviewed and published by the Institute of Research Advances (IRA) are the views and opinions of their respective authors and are not the views or opinions of the IRA. The IRA disclaims of any harm or loss caused due to the published content to any party.

Institute of Research Advances is an institutional publisher member of Publishers Inter Linking Association Inc. (PILA-CrossRef), USA. The institute is an institutional signatory to the Budapest Open Access Initiative, Hungary advocating the open access of scientific and scholarly knowledge. The Institute is a registered content provider under Open Access Initiative Protocol for Metadata Harvesting (OAI-PMH).

The journal is indexed \& included in WorldCat Discovery Service (USA), CrossRef Metadata Search (USA), WorldCat (USA), OCLC (USA), Open J-Gate (India), EZB (Germany) Scilit (Switzerland), Airiti (China), Bielefeld Academic Search Engine (BASE) of Bielefeld University, Germany, PKP Index of Simon Fraser University, Canada. 


\title{
IRA-International Journal of Education $\Xi^{\circ}$ Multidisciplinary Studies
}

\begin{abstract}
The speech act of request is face-threatening by nature and an inappropriate request can cause offence to the hearer, particularly when s/he has higher authority (Economidou-Kogetsidis, 2011). E-mail is frequently used to facilitate communication between student and professor in Iraq. Iraqi EFL (English as a foreign language) learners face pragmatic difficulty in making proper requests to individuals of higher authority via e-mail. Some studies have been conducted on Arab EFL learners to uncover the pragmatic behaviour of these learners in real-life requests using elicited data. This research fills a gap in Interlanguage Pragmatics (ILP) literature in that it investigates the use of academic request in three diverse imposition levels (low, medium, and high) by Iraqi EFL learners when they communicate with their professors via e-mail. This study uses authentic data consists of 200 e-mails related to academic requests sent by Iraqi EFL learners to their professors. Besides, the study uses the CCSARP (crosscultural speech act realisation project) originally proposed by Blum-Kulka, House, and Kasper (1989) and modified later by Biesenbach-Lucas (2007). Qualitative and quantitative analyses are used to analyse the data. The findings reveal that Iraqi EFL learners primarily use direct strategy in all types of request impositions by e-mail. These learners have socio-pragmatic deficiency in high imposition requests; that is, they are mainly direct with their professors in requests call for conventional indirectness to be acceptable pragmatically.
\end{abstract}

Keywords: Academic request, authentic data, directness level, EFL context, e-mail corpus, imposition level, sociopragmatics, student-professor interaction.

\section{Introduction}

The nature of the speech act of request implies a threatening tone that does not preserve the hearer's face (Woodfield, 2012). It can elevate the impositive force if produced improperly. This issue is particularly serious in the academic relationship between student and professor. Iraqi EFL learners are not acquainted with L2 socio-pragmatic values and thus behave inappropriately when they produce a request act to an individual of higher authority. If the student produces an improper request, the professor considers it a lack of respect and will not comply. Academic requests have different levels of imposition. Failure to produce requests that suit the imposition level can lead to socio-pragmatic deficiency. Iraqi EFL learners have insufficient socio-pragmatic knowledge because they do not consider the imposition level of some requests when they issue them to their professors by e-mail. This study demonstrates how Iraqi EFL learners use the request strategies in relation to the imposition level and whether such requests are proper pragmatically.

\section{Literature Review}

The speech act of request is considered the most problematic act for ESL (English as a second language)/EFL learners (Abdul Sattar, Lah, and Suleiman, 2009). This is because it requires them to have adequate pragmatic competence at the pragmalinguistics and socio-pragmatics levels. Pragmalinguistics and socio-pragmatics are two important concepts of pragmatic competence (Leech, 1983; Thomas, 1983). Pragmalinguistics is “...the particular resources which a given language provides for conveying particular illocution" (such as the linguistic strategies) Leech (1983, p. 11). Socio-pragmatics is the use of linguistic aspects in relation to social context; that is, using utterances with regard to social factors (power, distance, and imposition...etc) in a particular context (Leech, 1983). Blum-Kulka et al. (1989) designed the CCSARP to examine the speech act of request at the pragmalinguistic and socio-pragmatic levels of competence.

A wide range of studies (e.g., Blum-Kulka and Olshtain, 1986; Faerch and Kasper, 1989; Fukushima, 2003; Economidou-Kogetsidis, 2008, 2009, 2012; Hassall, 2003, 2012; Woodfield, 2012) used Blum-Kulka et al.'s (1989) CCSARP to investigate the speech act of request produced by native and non-native speakers of English. The discourse completion task and role-play are used to examine the request in these studies.

In addition, the speech act of request has been investigated using authentic data (e.g. e-mail) to examine the pragmatic problems of native and non-native speakers. Blum-Kulka et al.'s (1989) CCSARP is employed to examine the request utterances by e-mail. It was examined cross-linguistically among different languages and its validity in application was confirmed by the above-mentioned scholars. Moreover, the CCSARP is chiefly adapted by Biesenbach-Lucas (2007) to fit the e-mail data.

The earliest research on authentic e-mails was carried out by Hartford and Bardovi-Harlig (1996). These scholars examined the request act in student-professor relationships by native speakers of English and ESL learners. The findings revealed that ESL learners had pragmatic deficiency due to their misunderstanding of the imposition 


\section{IRA-International Journal of Education $\Xi^{\circ}$ Multidisciplinary Studies}

involved. Moreover, the learners' requests included limited softening devices, individual needs, and preposterous time-frame.

Chen (2006) examined the request act in a longitudinal study on a Taiwanese learner in an American context. The speech act of request was analysed based on a critical discourse analysis. The findings revealed that the learner encountered pragmatic problems in e-mails with an individual of higher authority. The study also showed some pragmatic development in the learner's behaviour due to her interaction in a L2 context.

Moreover, Biesenbach-Lucas (2007) examined the speech act of request by native speakers of English and international ESL learners in an American setting. Biesenbach-Lucas modified the original framework of CCSARP of Blum-Kulka et al. (1989) to be suitable for her data. She collected 355 authentic e-mails from native speakers of English and international learners. Three types of academic requests were identified: meeting, feedback, and extension. These requests had been rated as having low, medium, and high imposition degrees respectively. The findings showed that the subjects tended to be more direct in requests for meetings and feedback. In contrast, they resorted to conventional indirectness in requesting extensions. Even so, native speakers produced more polite forms of request than ESL learners. It was also revealed that syntactic devices were used to reduce the request illocutionary force while the use of lexical devices did not decrease in line with increasing the level of imposition.

Other research was conducted by Economidou-Kogetsidis (2011) to analyse the request strategies and lexical devices used by Greek EFL learners of English in e-mails. Economidou-Kogetsidis (2011) employed the CCSARP originally designed by Blum-Kulka et al. (1989) and adapted later by Biesenbach-Lucas (2007). Two hundred e-mails were collected from the learners. Low and high imposition requests were analysed. The findings uncovered that the learners had a tendency to be more direct in low and high imposition requests. Mood derivables, direct questions, and want statements were the most favoured direct sub-strategies in requesting. The findings unveiled that the learners' requests were improper when issued to an individual of higher authority because they were more direct and lacked lexical mitigated devices.

Pan (2012) investigated the speech act of request used by native speakers of English and Chinese non-native speakers of English using an electronic elicited e-mail. Pan (2012) adapted the CCSARP of Blum-Kulka et al. (1989). One hundred and eighty e-mails were collected. The findings concluded that Chinese non-native speakers of English controlled the pragmalinguistics aspects fairly well but revealed shortcomings in producing adequate syntactic devices. In addition, Chinese non-native speakers of English had tendency to use more lexical devices and external modifiers in their requests.

Najeeb et al. (2012) carried out research on Arab ESL learners to study the speech act of request in supervisee-supervisor relationships in Malaysia. Blum-Kulka et al.'s (1989) CCSARP was employed to study the directness level while Brown and Levinson's (1987) model of politeness was used to examine the politeness strategies. Twenty natural e-mails were collected to examine the requests. The findings revealed that Arab ESL learners tended to be more direct in requesting and miscommunication occurred between the supervisee and supervisor during communication by e-mail.

A point worth making is that some scholars (e.g. Al-Momani, 2009; Abdul Sattar et al. 2009; Umar, 2004) had investigated the requests produced by Arab EFL/ESL learners, using some elicited data. However, analysing natural requests by Arab EFL/ESL learners has not been the focus of researchers. Therefore, the current research fills a gap in ILP literature because it investigates three types of real academic requests produced by Iraqi EFL learners when they interact with their professors via e-mail. That is, this study examines the use of request strategies with the imposition level by Iraqi EFL learners in student-professor e-mail communication.

This study aims to:

1. Investigate the directness level that Iraqi EFL learners employ when they issue low, medium, and high academic requests to professors by e-mail.

2. Examine the sub-strategies that Iraqi EFL learners employ when they issue low, medium, and high academic requests to professors by e-mail.

\section{Methodology}

The e-mails are collected from 50 postgraduate Iraqi EFL learners at the Department of English, College of Arts, University of Baghdad during 2015 and 2016. The age range of these students is 22-23. All of these students are native speakers of Iraqi Arabic and are interested in English language and literature. Three professors have provided 
the researcher with e-mails of their students. A consent form is provided by the professors and students as well. The identities of the professors and their students are kept anonymous for ethical and privacy reasons. Firstly, 280 e-mails are collected. E-mails are selected purposefully based on the objectives of this study. Only academic e-mails are considered and any personal e-mails are not taken into account. The researcher has copied and pasted the e-mails into a word document file. A number is assigned to each e-mail for ease of identification. Thus, the total number of emails is 200 only. This number reached saturation, whereby any additional data would not reveal any new patterns (Guest, Bunce, and Johnson, 2006). The researcher has adopted the CCSARP originally suggested by Blum-Kulka et al. (1989) and modified later by Biesenbach-Lucas (2007) to fit the e-mail data. The CCSARP is a trusted scheme that is used in cross-linguistic experiments by a large number of scholars in a great deal of research (as stated earlier). This coding scheme examines the request act at the pragmalinguistic (linguistic aspects) and socio-pragmatic levels (social factors). It is the most prominent coding scheme in cross-cultural and ILP research (Barron, 2003).

\section{Data Analysis}

Qualitative and quantitative analyses are employed in this research. The former is used to identify the level of directness and strategy type of request based on the CCSARP. The requests are categorised into three different types: meeting, comment, and extension. These requests are labelled into three diverse imposition levels (low, medium, and high) respectively based on Biesenbach-Lucas's (2007) classification of request imposition degrees. In addition, quantitative analysis is employed to reveal if there is any statistically significant difference(s) among the super/sub categories in each request type. This can be accomplished using Chi-square test $\left(\chi^{2}\right)$, which is the suitable test for nominal data.

The unit of analysis in requesting is the discourse sequence, which is the sequence of expressions used by speakers (Blum-Kulka et al. 1989). The CCSARP categorises the head act of requesting into three levels of directness (super-strategies) and each level includes certain sub-strategies as in the following:

1. Direct: The most explicit and direct level that involves mood derivable, explicit performative, hedged performative, locution derivable, want statement, need statement, direct question, and expectation statement.

2. Conventional indirect: The request is realised by conventionalised linguistic means that include suggestory formulae and query preparatory (ability, permission, possibility, and willingness).

3. Nonconventional indirect: The request is realised by hints.

Moreover, the coding scheme is expanded to meet the requirements of data analysis. This involves request query preparatory (Hassall, 2003). Hassall (2003) categorises the query preparatory into ability (e.g. 'can/may you') and permission ('can/may I') in requesting. In the former the speaker asks the hearer's ability to do the action, while in the latter the speaker asks permission from the hearer to do the action. After adapting the coding scheme, some categories are found. These comprise query preparatory/mitigated preparatory (conventional indirectness) and nonverbal request (nonconventional indirectness). These categories are not available in the CCSARP before. The coding scheme has been checked and examined by three inter-raters for relaibility purposes.

\section{Results and Analysis}

\section{Meeting request}

Figure (1) shows that there is a statistically significant difference among the super strategies in meeting request and the direct strategy has the highest occurrence as compared to conventional indirect and nonconventional indirect strategies.

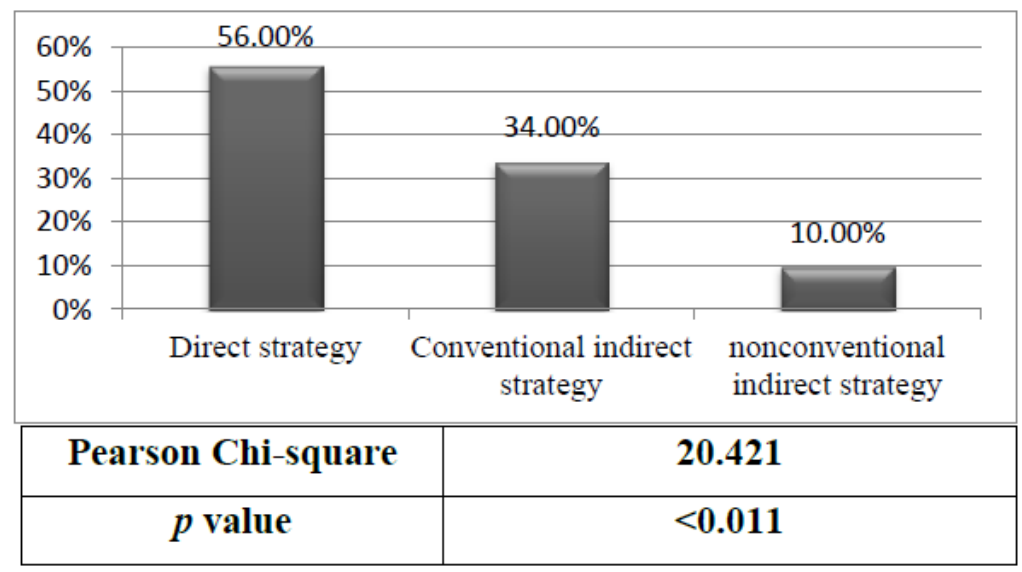

Figure1: Super Strategies (Meeting Request) 
Table (1) discloses that explicit performatives, hedged performatives, and want statements are statistically significant in meeting requests. The highest occurrence is noted in want statements, followed by hedged performatives and explicit performatives. Here are some examples of these sub-strategies produced by Iraqi EFL learners in their e-mails:

"Please I want to see you this week to discuss my paper with you if you don't mind" (Want statement)

"I would like to ask you a meeting if you don't mind" (Hedged performative)

"I ask you to meet me" (Explicit performative).

Table 1: Direct Sub-strategies

\begin{tabular}{cccc}
\hline \hline Strategy & Percentage & Pearson Chi-square & $p$ value \\
\hline Mood derivable & $13.4 \%$ & 3.542 & 0.112 \\
Explicit performative & $\mathbf{4 . 3 \%}$ & $\mathbf{4 . 6 0 1}$ & $\mathbf{0 . 0 2 2}$ \\
Hedged performative & $\mathbf{3 0 . 4 \%}$ & $\mathbf{6 . 4 9 9}$ & $\mathbf{0 . 0 2 1}$ \\
Locution derivable & $4.3 \%$ & 0.388 & 0.312 \\
Want statement & $\mathbf{3 4 . 8 \%}$ & $\mathbf{9 . 7 9 1}$ & $\mathbf{0 . 0 0 1}$ \\
Need statement & $4.3 \%$ & 1.345 & 0.332 \\
Direct question & $4.3 \%$ & 2.867 & 0.201 \\
Expectation statement & $4.3 \%$ & 0.823 & 0.324 \\
\hline \hline
\end{tabular}

As for conventional indirect sub-strategies, Table (2) reveals that query preparatory/permission and query preparatory/mitigated preparatory are statistically significant in meeting requests. The percentage of permission is higher than the percentage of mitigated preparatory. The following are examples of these sub-strategies in e-mails:

“Can I come to see you?" (Query preparatory/permission)

"I wonder if you can delay the meeting to another day because urgent circumstances

happened to me" (Query preparatory/mitigated preparatory).

Table 2: Conventional Indirect Sub-strategies

\begin{tabular}{cccc}
\hline \hline Strategy & Percentage & Pearson Chi-square & $p$ value \\
\hline Suggestory formulae & $7.1 \%$ & 7.765 & 0.199 \\
QP/Ability & $14.2 \%$ & 0.345 & 0.123 \\
QP/Permission & $\mathbf{5 7 \%}$ & $\mathbf{8 . 6 5 4}$ & $\mathbf{0 . 0 1 1}$ \\
QP/Possibility & $0 \%$ & 1.234 & 0.212 \\
QP/Willingness & $7.1 \%$ & 1.134 & 0.156 \\
QP/Mitigated & $\mathbf{1 4 . 2 \%}$ & $\mathbf{0 . 2 3 4}$ & $\mathbf{0 . 0 0 9}$ \\
Preparatory & & & \\
\hline \hline
\end{tabular}

As for nonconventional indirect strategies, there is no a statistically significant difference between hints and nonverbal requests.

\section{Comment request}

Figure (2) shows that there is a statistically significant difference among the super-strategies and the highest occurrence is in the direct strategy, followed by nonconventional indirect and conventional indirect strategies. 
IRA-International Journal of Education $\Xi^{0}$ Multidisciplinary Studies

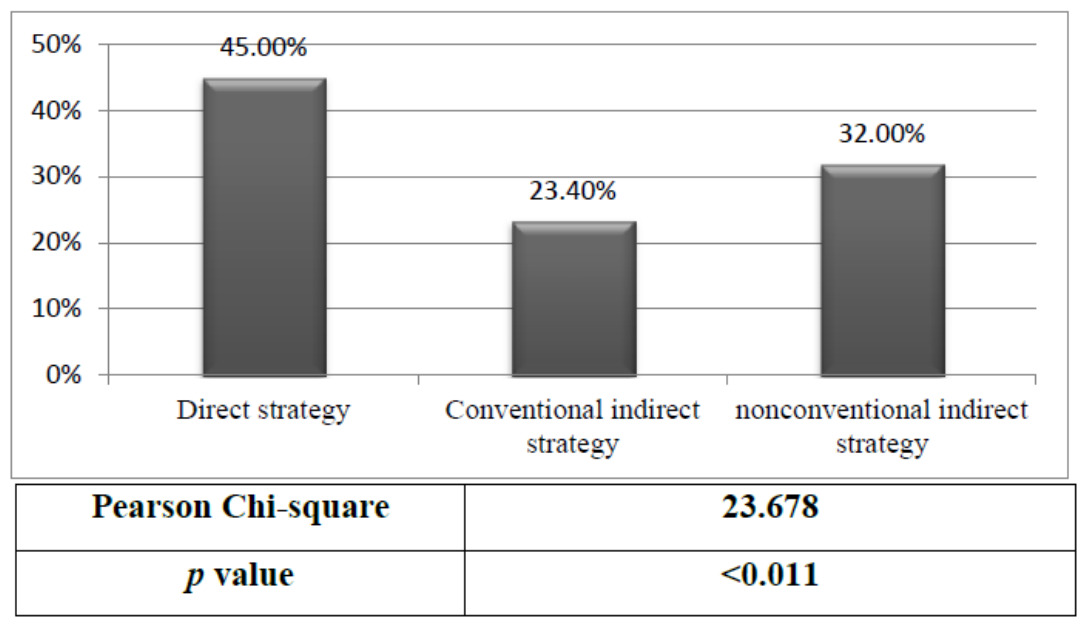

Figure 2: Super Strategies (Comment Request)

Regarding direct sub-strategies, Table (3) reveals that want statements, which have the highest percentage, and direct questions are statistically significant in the meeting requests. Examples of these sub-strategies are presented below:

"Please I want your comment on my section 2" (Want statement)

"Do I need to add another reference?" (Direct question)

Table 3: Direct Sub-Strategies

\begin{tabular}{lccc}
\hline \hline \multicolumn{1}{c}{ Strategy } & Percentage & Pearson Chi-square & $p$ value \\
\hline Mood derivable & $23.8 \%$ & 1.787 & 0.160 \\
Explicit performative & $4.8 \%$ & 0.764 & 0.341 \\
Hedged performative & $19 \%$ & 0.786 & 0.874 \\
Locution derivable & $0 \%$ & 0.842 & 0.578 \\
Want statement & $\mathbf{3 8 \%}$ & $\mathbf{0 . 5 6 7}$ & $\mathbf{0 . 0 0 4}$ \\
Need statement & $4.8 \%$ & 1.564 & 0.250 \\
Direct question & $\mathbf{4 . 8 \%}$ & $\mathbf{5 . 0 4 3}$ & $\mathbf{0 . 0 0 6}$ \\
Expectation & $4.8 \%$ & 1.564 & 0.298 \\
statement & & & \\
\hline \hline
\end{tabular}

Moreover, Table (4) displays that query preparatory/possibility is statistically considerable; e.g., "Is it possible to send me your notices on my research?".

Table 4: Conventional Indirect Sub-Strategies

\begin{tabular}{cccc}
\hline \hline Strategy & Percentage & Pearson Chi-square & $p$ value \\
\hline Suggestory formulae & $0 \%$ & 1.454 & 0.234 \\
QP/Ability & $18.1 \%$ & 2.454 & 0.453 \\
QP/Permission & $27.2 \%$ & 1.765 & 0.135 \\
QP/Possibility & $\mathbf{9 \%}$ & $\mathbf{5 . 2 3 4}$ & $\mathbf{0 . 0 1 1}$ \\
QP/Willingness & $9 \%$ & 1.678 & 0.234 \\
QP/Mitigated & $36.3 \%$ & 0.876 & 0.366 \\
Preparatory & & & \\
\hline \hline
\end{tabular}

Concerning nonconventional indirectness, there is no statistically considerable effect for the sub-strategies in comment request as there is no significant diversity between hints and nonverbal requests. 


\section{Extension request}

Figure (3) reveals that there is a statistically significant difference among the super-strategies and the direct strategy has the highest percentage as compared to conventional indirect and nonconventional indirect strategies.

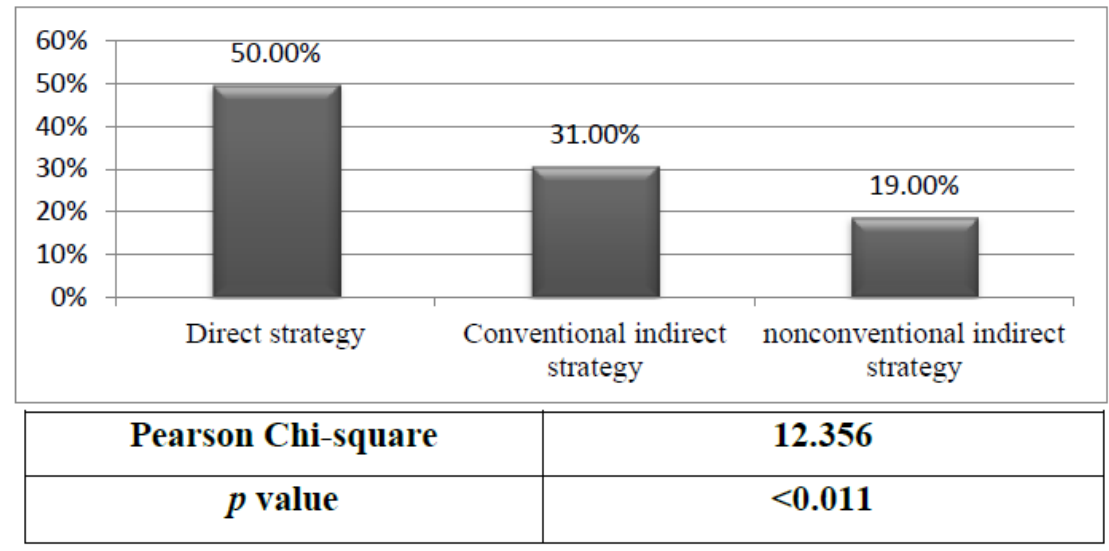

Figure 3: Super Strategies (Extension Request)

Table (5) demonstrates that explicit performatives, hedged performatives, and want statements are statistically significant. The want statement has the highest occurrence, followed by explicit performative and hedged performative. For example:

"I want to extend the deadline of submitting my paper because I have private circumstances" (Want statement),

"Excuse me Dr. I ask you an extension just for 2 weeks if it is possible" (Explicit performative)

"Please I would like you to give one more week to complete my paper if it is possible" (Hedged performative)

Table 5: Direct Sub-Strategies

\begin{tabular}{lccc}
\hline \hline \multicolumn{1}{c}{ Strategy } & Percentage & Pearson Chi-square & $p$ value \\
\hline Mood derivable & $12.5 \%$ & 0.076 & 0.654 \\
Explicit & $\mathbf{1 8 . 8 \%}$ & $\mathbf{9 . 3 4 2}$ & $\mathbf{0 . 0 0 2}$ \\
performative & & & \\
Hedged & $\mathbf{1 2 . 5 \%}$ & $\mathbf{4 . 7 8 6}$ & $\mathbf{0 . 0 1 1}$ \\
performative & $0 \%$ & 1.231 & 0.234 \\
Locution derivable & $\mathbf{5 6 . 3 \%}$ & $\mathbf{8 . 3 0 0}$ & $\mathbf{0 . 0 0 3}$ \\
Want statement & $0 \%$ & 4.744 & 0.127 \\
Need statement & $0 \%$ & 2.012 & 0.145 \\
Direct question & $0 \%$ & 4.234 & 0.097 \\
Expectation & & & \\
statement & &
\end{tabular}

As for conventional indirect sub-strategies, Table (6) reveals that query preparatory/ability is statistically significant; e.g., "Could you give me an extension if you don't mind?".

Table 6: Conventional Indirect Sub-Strategies

\begin{tabular}{cccc}
\hline \hline Strategy & Percentage & Pearson Chi-square & $p$ value \\
\hline Suggestory formulae & $0 \%$ & 1.654 & 0.567 \\
& & & $\mathbf{0 . 0 0 2}$ \\
QP/Ability & $\mathbf{4 0 \%}$ & $\mathbf{6 . 5 6 4}$ & 0.065 \\
QP/Permission & $40 \%$ & 6.459 & 0.123 \\
QP/Possibility & $0 \%$ & 4.234 & 0.765 \\
QP/Willingness & $0 \%$ & 3.123 & 0.123 \\
QP/Mitigated & $20 \%$ & 0.234 & \\
Preparatory & & & \\
\hline \hline
\end{tabular}




\section{IRA-International Journal of Education $\Xi^{\circ}$ Multidisciplinary Studies}

Concerning nonconventional indirect strategy, there is no a statistically considerable diversity between hints and nonverbal requests.

\section{Discussion}

The direct strategy is evidently the prominent strategy in all the request types. The level of directness performed by Iraqi EFL learners is more direct than conventional indirect and nonconventional indirect in meeting, comment, and extension requests. This unveils that Iraqi EFL learners have socio-pragmatic competence when they use the request strategies in requesting meetings and comments that have low and mid imposition levels respectively. This is because such requests do not require high politeness levels. This is in line with Biesenbach-Lucas's (2007) finding, where native and non-native speakers tended to be direct in requesting appointments and feedback from their professors. Biesenbach-Lucas (2007) states that the professor should have office hours for meeting his/her students so that s/he can provide his/her students with feedback on their research, which does not require high levels of politeness in requesting.

In contrast, Iraqi EFL learners have insufficient socio-pragmatic competence in requesting an extension because they resort to direct strategy rather than conventional indirect strategy. The extension request has a high imposition level which calls for conventional indirectness to be acceptable pragmatically. This does not correspond to Biesenbach-Lucas's (2007) finding, where native and non-native speakers tended to use more conventional indirectness than directness or nonconventional indirectness in requesting an extension from their professors by email. Biesenbach-Lucas (2007) argues that the professor is under no obligation to grant the student an extension because it is the student who transgresses the course policy.

These learners prefer to be more direct in all the request types because they might be influenced by their Iraqi culture and incline to use more direct sub-strategies that are customary forms in their Iraqi Arabic, such as want statement, mood derivable, and explicit performative. These learners sometimes use the conventional indirect super strategy in the request types but not as much as they use the direct super strategy. While they significantly tend to use query preparatory/ permission and mitigated preparatory in requesting meeting, they resort to query preparatory/possibility and query preparatory/ability for requesting comments and extensions respectively. This unveils that these learners consider the type of request they are making because they find that they need to ask permission from their professors to have meetings. While for comments and extensions, they ask about the professor's possibility and ability to do the action. This is because requesting a meeting is related to the speaker's permission, while requesting comments and extensions pertained to the hearer's capacity. The mitigated preparatory is significantly used in meeting requests to soften the illocutionary force of the request.

In addition, Iraqi EFL learners employ more hints in feedback request. A hint is a mechanical form and it is normally employed in e-mail as the professor is familiar with it and the meaning can be understood from the context. Yet, these learners employ few hints in extension requests. This shows their socio-pragmatic deficiency because it is plausibly presumed that more hints should be used in requesting an extension to avoid making the unsuitable request. Furthermore, the dominant use of direct strategy is related to the culture of Iraqi EFL learners. Iraq is a collectivistic culture that concentrates on the orientation of positive face and gives regard to in-group relations and solidarity issues which are opposed to individualistic culture (Aldhulaee, 2011; Al-Zubaidi, 2011). In a similar vein, EconomidouKogetsidis (2008) underlines that the culture in Greece inclines to positive politeness as dissimilar to an individualistic (British) culture, which tends to negative politeness, tact, and avoiding obligation. Therefore, Iraqi EFL learners mainly resort to directness in all request types, neglecting the high level of extension requests which in turn causes inappropriateness.

\section{Conclusion}

The findings unveil that Iraqi EFL learners have socio-pragmatic deficiency in issuing academic requests to their professors. They strongly prefer the use of direct strategy in high imposition requests that require conventional indirectness in order to be acceptable pragmatically. Issuing a request to a higher authority requires higher sociopragmatic competence. These learners have limited pragmatic knowledge in using conventional indirectness. Moreover, Iraqi EFL learners revert to their L1 and culture in producing L2 requests, which in turn makes their requests out of status. These learners have limited chances to interact in an L2 context which, in turn leads to inappropriateness in the requests they produced. 


\section{IRA-International Journal of Education $\Xi^{\circ}$ Multidisciplinary Studies}

\section{References}

[1] Abdul Sattar, H. Q., Lah, S. C.,\& Suleiman, R. R. R. (2009). Iraqi postgraduates' production and perception of requests: A pilot study. The International Journal of Language Society and Culture, 29, 56-70.

[2] Aldhulaee, M. T. (2011). Request mitigating devices in Australian English and Iraqi Arabic: A comparative study (Master thesis). Retrieved May 5, 2016 from https://dro.deakin.edu.au/eserv/DU:30052041/aldhulaee-requestmitigating2011.pdf.

[3] Al-Momani, H. S. (2009). Caught between two cultures: The realization of requests by Jordanian EFL learners (Doctoral dissertation).

Retrieved March 17, 2014, from http://dspace.iup.edu/bitstream/handle/2069/176/Husam\%20Al-Momani.pdf? sequence $=1$.

[4] Al-Zubaidi, N. (2012). Expressions of gratitude in American English and Iraqi Arabic.Interlanguage and cross-cultural pragmatics perspectives.Deutschland,Germany: Lambert Academic Publishing.

[5] Barron, A. (2003). Acquisition in interlanguage pragmatics.Learning how to do things with words in a study abroad context. Philadelphia, USA: John Benjamins Publishing Company.

[6] Biesenbach-Lucas, S. (2007). Students writing emails to faculty: An examination of e-politeness among native and nonnative speakers of English. Language Learning \&Technology, 11(2), 59-81.

[7] Blum-Kulka, S., \&Olshtain, E. (1986). Too many words: Length of utterance and pragmatic failure. Studies in Second Language Acquisition, 8(02), 165-179.

[8] Blum-Kulka, S., House, J., \& Kasper, G. (1989).Investigating cross-cultural pragmatics: An introductory overview. In S. Blum-Kulka, J. House, \& G. Kasper (Eds.), Cross-cultural pragmatics: Requests and apologies (Vol. XXXI, pp. 1-34, 275-289). Norwood, NJ: Ablex.

[9] Brown, P., \& Levinson, S. C. (1987). Politeness: Some universals in language usage (Vol. 4). Cambridge: Cambridge University Press.

[10] Chen, C. E. (2006). The development of e-mail literacy: From writing to peers to writing to authority figures. Language Learning \& Technology, 10(2), 35-55.

[11] Economidou-Kogetsidis, M. (2008). Internal and external mitigation in interlanguage request production: The case of Greek learners of English. Journal of Politeness Research,4(1), 111-138.

[12] Economidou-Kogetsidis, M. (2009). Interlanguage request modification: The use of lexical/phrasal downgraders and mitigating supportive moves.Multilingua, 28(1), 79-112.

[13] Economidou-Kogetsidis, M. (2011). Please answer me as soon as possible: Pragmatic failure in non-native speakers' email requests to faculty. Journal of Pragmatics, 43(13), 3193-3215.

[14] Economidou-Kogetsidis, M. (2012).Modifying oral requests in a foreign language: The case of Greek Cypriot learners of English. In M. Economidou-Kogetsidis \& H. Woodfield (Eds.), Interlaguage request modification (pp. 163-202). Philadelphia, USA: John Benjamins Publishing Company.

[15] Faerch, C., \& Kasper, G. (1989).Internal and external modification in interlanguage request realization.In Blum-Kulka, S., House, J., \& Kasper, G. (Eds.), Cross-cultural pragmatics: Requests and Apologies (pp. 221-247). Norwood, NJ: Ablex.

[16] Fukushima, S. (2003). A cross-cultural study of requests: The case of British and Japanese undergraduates. In K. M. Jaszczolt and K. Turner (Eds.), Meaning through language contrast (Vol.2, pp. 263-276). Philadelphia, USA: John Benjamins Publishing Company.

[17] Guest, G., Bunce, A., \& Johnson, L. (2006). How many interviews are enough? An experiment with data saturation and variability. Field Methods, 18(1), 59-82.

[18] Hartford, B. S., \&Bardovi-Harlig, K. (1996). At your earliest convenience: A study of written student requests to faculty. In L. F. Bouton (Ed.), Pragmatics and language learning (Vol.7, pp. 55-69). Urbana-Champaign: Division of English as an International Language.

[19] Hassall, T. (2003).Requests by Australian learners of Indonesian.Journal of Pragmatics, 35(12), 1903-1928.

[20] Hassall, T. (2012).Request modification by Australian learners of Indonesian. In M. Economidou-Kogetsidis \& H. Woodfield (Eds.), Interlanguage request modification (pp. 203-242). Philadelphia, USA: John Benjamins Publishing Company.

[21] Leech, G. (1983). Principles of pragmatics. London: Longman.

[22] Najeeb, Z. M., Maros, M., \&Nor, N. F. M. (2012). Politeness in e-mails of Arab students in Malaysia.GEMA: Online Journal of Language Studies, 12(1),125-145.

[23] Pan, P. C. (2012). Interlanguage requests in institutional e-mail discourse: A study in Hong Kong. In M. EconomidouKogetsidis \& H. Woodfield (Eds.), Interlanguage request modification (pp. 119-162). Philadelphia, USA: John Benjamins Publishing Company.

[24] Thomas, J. (1983). Cross-cultural pragmatic failure.Applied Linguistics, 4(2), 91-112.

[25] Umar, A. A. (2004). Request strategies as used by advanced Arab learners of English as a foreign language. Umm AlQura University Journal of Educational \& Social Sciences \& Humanities, 16(1), 42-87.

[26] Woodfield, H. (2012). "I think maybe I want to lend the notes from you". Development of request modification in graduate learners. In M. Economidou-Kogetsidis \& H. Woodfield (Eds.), Interlanguage request modification (pp. 9-50). Philadelphia, USA: John Benjamins Publishing Company. 